\title{
Ueber das Verhalten der Quecksilberoxydulsalze gegen Natron und Ammoniak; \\ roul
}

\section{Barfoed.}

(Unter Mitwirkung des Verfassers übersetzt von Dr. Andreas Fetersen.)

I.

\section{Der Natromuiederschlag der Quecksilberoxydulsalze.")}

Mehrere Umstände deuten darauf hin, dass der Niederschlag, welcher bei der Behandlung der Quecksilberoxydulverbindungen mit Kali entsteht, freies Quecksilber in fein vertheiltem Zustande enthält. Man sieht gewöhnlich den frischen Niederschlag für Quecksilberoxydul an, und nimmt an, dass die Anwesenheit des freien Quecksilbers cladurch bedingt ist, dass ein Theil des Quecksilberoxyduls sich in ein Gemenge von Quecksilber und Quecksilberoxyd umgesetzt hat, und dass die ganze Art und Weise, nach welcher gearbeitet wird, auf das Verbältniss, worin diese Bestandtheile im fertigen Präparate vorhanden sind, influirt. Doch hat schon Guibourt im Jahre 1816 der Anschaung Ausdruck gegeben, dass das Quecksilberoxydul nicht auf die angeführte Weise dargestellt werden kann (ne peut être obteru isolé), und dass der Niederschlag nur ein Gemisch von Quecksilber und Quecksilberoxyd ist. Hierbei stützt er sich auf folgende Thatsachen; der Niederschlag, welchen er aus salpetersaurem Quecksilberoxydul und Kali dargestellt hatte, bildete erstens durch Behandeln mit Chlorwasserstoffsäure sowohl Queck-

1) Mitgetheilt in der Sitzung der königlichen dänisehen Gegellschaft der Wissenschaften am 23. November 1883. Gedruckt in: Oversigt over det kongelige danske Videnskabernes Selnkabs Ferhandlinger, Kjóbenhavn 1883, S. 111. Der deutschen Cebcrsetzung sind einige spätere Zusitze rom Verfasser angekü̈pft, die jedoch immer als solche bezeichnet sind. 
silberchlorür als Quecksilberchlorid, und zweitens zeigte er nach dem Auswaschen und Trocknen unter der Lupe kleine Quecksilberkugeln. Gay-Lussac, der über die Versuche Guibourt's berichtete ${ }^{1}$ ) und dieselben bei gewöhnlicher Temperatur und im Dunkeln wiederholte, kam zu demselben Resultat und bemerkt, dass man nicht aus dem Umstande, dass der Niederschlag durch Behandeln mit Salzsäure Quecksilberchlorür bildet, schliessen dürfe, er enthalte Quecksilberoxydul; denn das fein vertheilte Quecksilber wirkt leicht auf das Chlorid unter Bildung von Quecksilberchlorür ein, Diese Anschaungsweise Guibourt's fand nicht allgemeine Zustimmung - ihr wird zwar ohne Vorbehalt von Thénard in seinem Traité de climie T.II, 1824 beigetreten, sie wird aber gar nicht von Berzelius in seinem Lehrbuche der Chemie, Bd. 3, 1834 erwähnt - und obgleich sie im Jahre 1845 eine neue Stütze erhielt, indem Lefort beobachtete, dass ein Goldblech durch alle solche Niederschläge, welche sonst für Quecksilberoxydul angesehen wurden, weiss wurde ${ }^{2}$ ), so ist sie auch später nicht berücksichtigt worden. Es ist auch nicht zu leugnen, dass alle jene Versuche viel zu wünschen übrig liessen, und dass man zuviel aus ihnen geschlossen hat. Man vermisst z. B. Auskunft darüber, wie lange das Auswaschen und Trocknen der Niederschläge gedauert hat und überhaupt darüber, wie alt sie bei der Untersuchung waren, was doch in diesen und ähnlichen Fällen nicht unwesentlich ist, da ein älterer Niederschlag etwas anderes, als ein frischer sein kann, wie ja auch eine vielleicht erst später eingetretene Aenderung nicht genügt, die Existenzfähigkeit des freien Quecksilberoxyduls ganz zu leugnen. Ferner hat man auch zu viel aus den Versuchsresultaten geschlossen; denn daraus, dass der Niederschlag freies Quecksilber und Quecksilberoxyd enthält, folgt nicht, dass er allein daraus besteht, woran übrigens auch das spec. Gew. desselben (nach Karsten 8,95 , nach Herapath 10,69 ; siehe auch w. u.) Zweifel hervorrufen muss. Andererseits sind aber auch die

1) Ann. Chim. 1, 422.

2) Journ. de pharmacie ct de chimie, 1845, S. 6 et 16 . 
Beweise, welche man aus dem chemischen Verbalten des Niederschlags in Bezug auf seinen Gehalt an Quecksilberoxydul hat ziehen wollen, sehr schwach (s. unten).

$\mathrm{Da}$ nach dem Vorangehenden die Beschaffenheit der Niederschläge der Quecksilberoxydulsalze mit Alkalien für ungenügend bekannt angesehen werden muss, so habe ich eine Untersuchung derselben angestellt, deren Resultate hier mitgetheilt werden. In dieser Abhandlung wird allein der Natronniederschlag besprochen, mit dem wohl die durch die anderen nicht flüchtigen Alkalien hervorgebrachten Niederschläge übereinstimmen. Den Ammoniakniederschlag, der bekanntlich eine ganz verschiedene Beschaffenheit hat, werde ich in einer zweiten Abhandlung einer Besprechung unterziehen.

I. Die erste sich aufdrängende Frage ist die folgende: Ist der Natronniederschlag in ganz frischem Zustande ein Gemisch, oder bestimmter, enthält er freies Quecksilber? Die Antwort ist eine entschieden bejahende, denn der Niederschlag vermag gleich bei seiner Bildung Gold zu amalgamiren. Bei den diesbezüglichen Versuchen habe ich ein Blech von reinem Golde verwendet, auf welches ich zuerst das betreffende Quecksilbersalz und dann, bei gewöbnlicher Temperatur und gegen Licht geschützt, Natronhydrat gebracht habe. Bei jedem Versuche wurde die alkalische Mischung weggespült, und das Goldblech zum weiteren Gebrauche in einer Gasflamme ansgeglüht und mit einem Achatpistill auf den Stellen wieder glatt gemacht, wo es vom Quecksilber angegriffen und deshalb etwas matt war, wobei übrigens zu bemerken ist, dass solches mattes Gold, welches auch durch Eintrocknen einiger Tropfen Goldchlorid auf dem Goldbleche und nachfolgendem Ausglühen hervorgebracht werden kam, bedeutend schneller als das blank polirte amalgamirt wird. Es wurden angewandt: salpetersaures, schwefelsaures und essigsaures Quecksilberoxydul, ferner Quecksilberchlorür ersteres als mittelstarke Lösung $(1: 20)$ die anderen in frisch gefälltem und ausgewaschenem Zustande. Bei allen trat die Amalgamirung schnell ein, etwa im Laufe einer halben Minute; dass aber die verschiedenen Salze sich in dieser 
Hinsicht etwas verschieden verhalten, kann nicht auffallen, wenn man die verschiedene Form ihrer Niederschläge beachtet. Das Sulfat z. B., welches, unter dem Mikroskope gesehen, in der Gestalt nadelförmiger Kryställchen, die sich in allen Richtungen kreuzen, hervortritt, giebt durch Zusatz von Natronhydrat einen voluminösen Niederschlag von gleichem Habitus, der offenbar nicht in so innige Berührung mit dem Golde kommen kann, als der dichtere, mehr zusammengeballte Niederschlag des Nitrats. Deshalb wird bei den krystallinischen Salzen die Amalgamirung etwas beschleunigt, wenn man vor dem Zusatze der Natronlauge dieselben mittelst eires Glasstabes fest gegen das Gold drückt, in diesem Falle kann die Reaction schon nach wenigen Secunden eintreten. Bei dem Nitrat und dem Chlorür dagegen tritt dieselbe so leicht und so schnell ein, dass man, selbst bei Verwendung eines einzelnen Tropfen des ersteren (nach einer besonderen Bestimmung mit einem Gehalte von etwa $1 \mathrm{Mgrm}$. trockenen Quecksilbersalzes) oder einer entsprechenden Menge des Chlorürs gleich nach dem $\mathrm{Zu}$ setzen der Lauge die Mischung wegspülen und einen sehr deutlichen Quecksilberfleck finden kann, obgleich die Berührung des Goldes mit der alkalischen Flüssigkeit kaum eine Secunde gedauert hat.

Es geht hieraus zweifellos hervor, dass der Niederschlag gleich nach seinem Entstehen freies Quecksilber enthält, und da die Amalgamirung, selbst bei ejner so geringen Stoffmenge und in so kurzer Zeit wie oben angeführt, eine sehr deutliche war, so kann kaum bezweifelt werden, dass die Menge des freien, metallischen Quecksilbers in dem ganz frischen Niederschlage ganz beträchtlich sein muss.

Es lag jetzt nahe, zu versuchen, ob man nicht durch Anwendung eines passenden Druckes das Quecksilber, welches ich weder durch die Lupe noch durch das Mikroskop direct sehen konnte, so in deutlichen Kugeln sammeln konnte, dass eine bessere Vorstellung über seine Menge zu erhalten war. Dieser Versuch gelang mir auch gut. Dadurch, dass ich nach schnellem Abgiessen der Flüssigkeit (dass hierdurch ein Theil des Niederschlages verloren geht, ist gleich- 
gültig) den Niederschlag auf ein Filter brachte, dieses zwischen Fliesspapier abdrückte und danach einen Glasstab über das auf einer Glasplatte ausgebreitete Pulver hin und her bewegte, oder dasselbe auf Papier ausstrich, konnte ich darin schon mit dem blossen Auge zahlreiche Quecksilberkugeln wahrnehmen. Ein solcher Versuch dauert, wenn alles im Voraus dazu vorbereitet ist, nicht fünf Minuten von dem Augenblicke an, wo die Natronlauge zugefügt wird bis zum Hervortreten des Quecksilbers, und da es kaum anzunehmen ist, dass der auf die feuchte Masse ausgeübte schwache Druck eine Spaltung des möglicher Weise vorhandenen Quecksilberoxyduls veranlassen kann, so geht hieraus hervor, dass der Niederschlag freies Quecksilber in ansehnlicher Menge enthält, wenn er auch nur wenige Minuten vorher gefällt ist. Dass dem Drucke keine andere Wirkung als die rein mechanische, das fein vertheilte Quecksilber zum Sammeln zu bringen, zugeschrieben werden darf, ergiebt sich auch aus einigen anderen Versuchen, bei welchen der Niederschlag in einer kräftigen Centrifuge (Radius 1', 2000 Umdrehungen in der Minute) behandelt wurde. Der frische, nur ausgewaschene Niederschlag, dessen Gewiclit in trocknem Zustande nachher 12-15 Grm. betrug, wurde, mit etwas Wasser angerührt, als ein dicker Brei in eine Flasche von der Form und der Grösse eines gewöhnlichen Reagircylinders gebracht. Die Flasche wurde dann in die Centrifuge, mit ihrem Boden gegen die Peripherie desselben gestützt, angebracht und in dieser Stellung in Bewegung gesetzt. Während der Bewegung, welche 15-30 Minuten fortgesetzt wurde, sammelte sich der Niederschlag selbstverständlich unter dem Wasser als dichte Masse, da diese aber wieder ausgespült wurde, waren auf dem Boden der Flasche hier und da Quecksilberkugeln deutlich zu beobachten.

Wie die Menge des freien Quecksilbers in diesem Niederschlage bestimmt werden kann, werde ich weiter unten besprechen.

II. Nach mehreren älteren Analysen, welche für richtig angesehen werden müssen, enthält der hier besprochene Niederschlag im trocknen Zustande nur Quecksilber und 
Sauerstoff, und zwar in einem Verhältnisse, wie zwischen 1 At. Sauerstoff und 2 At. Quecksilber. ${ }^{3}$ ) Hierans folgt, dass er, wenn er freies Quecksilber enthält, auch Quecksilberoxyd enthalten muss, welches auch durch das Verhalteu desselben gegen Salzsäure (s. unten) bestätigt wird. Dasselbe muss also auch für den ganz frischen Niederschlag gelten; dass er freies Quecksilber enthält, kann aber auch direct bewiesen werden, indem ein Theil des Quecksilberoxyds von dem übrigen Niederschlage isolirt werden kann. Während man nämlich einen! einfarbigen Niederschlag erhält, wenn man bei der Zerlegung des Salzes mit Alkali das Gemisch stark schüttelt oder umrührt ${ }^{2}$ ), eine Methode, welche man bei der Darstellung des Niederschlages: zu anderem Gebrauche wohl immer benutzen wird, da die Flüssigkeit sich auf diese Weise leicht klärt, so wird man, wenn man das Alkali ohne unnöthig starke Bewegung zusetzt, oft bemerken, dass die über dem dunklen Niederschlage stehende Flüssigkeit schmutziggelb ist und sich nur schwierig klärt. ${ }^{3}$ ) Wenn diese Flüssigkeit abgegossen und bei Seite gestellt wird, dann erhält man einen ebenfalls schmutziggelben Niederschlag, welcher unter dem Mikroskope bei direct auffallendem Sonnenlichte deutlich als aus einem gelben

1) Ueber die mögliche Ursache davon, dass andere Analysen einc'n Ueberschuss an Sauerstoff gegeben haben, selbst wenn die Niederschläge aus oxydfreien Quecksilberoxy dulsalzen hergestellt waren, sieht' weiter unten.

2) Im Anfang kann allerdings, wie schon von Donovan ungegeben, ein gelbbraunes, basisches Chlorid gebildet werden.

3) Wer einmal dies geschen hat (man sieht es besonders deutlich beim Zusetzen einer nicht $\mathrm{z} u$ starken Natronlauge zu einer grösseren Menge - etwa 15-20 Grm, - ausgewaschenen und mit viel Wasser angerührten Quecksilberchlorürs, bis derjenige Theil des Niederschlages, der sich leicht absetzt, schwarz ist) wird auch bemerken, dass die trübe Flüssigkeit, welche bei der Fällung kleiner Proben ohne starkes Schütte!n über dem dunklen Niederschlage steht, obwohl dunkel doch einen Stich ins Gelbliche besitzt, den man sonst kaum beobachten würde. Bei starker Bewegung verschwindet dieser gelbliche Ton, weil das fein vertheilte Quecksilberoxyd von dem übrigen Niederschlage eingebüllt und herabgezogen wird; die Flüissigkeit klärt sich dann auch leicht. 
und einem dunkeln .Körper bestehend erkannt wird; man sieht gelbe Flocken zwischen anderen mehr oder weniger grauen. ${ }^{1}$ ) Dass dieser Niederschlag nach dem Auswaschen, Behandeln mit schwacher und kalter Salzsäure und Abfiltriren einer relativ geringen Menge Quecksilberchlorürs, eine Lösung giebt, welche eine bedeutende Menge Quecksilberchlorid enthätt, also mit Ammoniak einen starken, weissen Niederschlag giebt u. s. w., kann nach dem oben Gesagten nicht überraschen.

$\mathrm{Zu}$ diesem directen Nachweise des Quecksilberoxyds muss noch die Bemerkung hinzugefügt werden, dass auch der ganz frische, auf gewöhnliche Weise und unter starkem Umschütteln dargestellte Niederschlag eine Lösung von Quecksilberchlorid geben kann, wenn er mit Salzsäure behanclelt wird. Wie S. 441 angegeben, ist dasselbe von Guibourt bei älteren Niederschlägen beobachtet worden; der Bericht darüber ist aber etwas unvollständig, indem er nur sagt, dass Quecksilberchlorür und Quecksilberchlorid gebildet wird; es hätte beigefügt sein sollen, dass etwas Quecksilber mit dem Chlorür gemischt zurück bleibt; sonst kann die Flüssigkeit kein Quecksilberchlorid enthalten, wenn sie nicht auf andere Weise oxydreich geworden wäre, z. B. dadurch, dass die Arbeit mit oxydhaltigem Salze angefangen wurde. - Ich werde weiter unten hierauf zurückkommen und bemerke hier nur, dass, wenn man reines Quecksilberchlorür mit Natronhydrat zersetzt und gleich danach verdünnte Salzsäure zusetzt, der dunkle Niederschlag bei kurzdauerndem Umsehütteln eine blaugraue Farbe annimmt, und dass, wenn man die Flüssigkeit fil-

2) In dem gewöhnlichen Niederschlage sieht man unter dem Mikroskope gar keine gelbe Beimengung. Im hellen Tageslichte, bei bedecktem Spiegel, also von oben belenchtet und in der Flüssigkeit, worin er gebildet wird, liegend ist er matt dunkelgrau, im Sonnenlichte unter denselben Bedingungen grauweiss, gleichförmig und so glänzend, dass man versucht werden könnte, denselben für aus lauter kleinen Quecksilberkügelchen bestehend anzuschen, weun man nicht wüsste, dass er nicht daraus allein bestehen kanm. Durch einige Versuche überzeugt man sich auch leicht, dass andere dunkle Niederschläge in derselben Beleuchtung ein ganz ähnliches Aussehen besitzen. 
trirt, das Filtrat eine erkennbare Menge Quecksilberchlorid enthält.

Bei den soeben besprochenen Versuchen, und ebenfalls im folgenden habe ich, wo nichts anderes angegeben ist, zur Darstellung der Niederschläge Quecksilberchlorür im frisch präcipitirten und nur ausgewaschenem Zustande benutzt. Ich habe dieses dem Nitrate vorgezogen, weil dieses leicht etwas Quecksilberoxyd enthalten kann, welches in den einzelnen Fällen die Erklärung der Reactionen unsicher machen würde. Das Auswaschen der Niederschläge geschah immer durch Dekantiren, um jede Einmischung organischer Substanzen zu vermeiden.

III. Ich gehe nun zur Prüfung der Frage über, ob der Niederschlag allein aus Quecksilber und Quecksilberoxyd oder zugleich aus Quecksilberoxydul besteht. Beim ersten Anblick kann es vielleicht so erscheinen, als wäre diese Frage nach den gewöhnlichen analytischen Methoden, also durch Behandeln mit Säuren, sehr leicht zu entscheiden; es muss aber daran erinnert werden, dass die Quecksilberoxydsalze in Wechselwirkung mit Quecksilber in Oxydulsalze übergeführt werden; der Niederschlag wird also, selbst wenn er kein Oxydul enthält, durch Behandeln mit Säuren Quecksilberoxydulsalze geben können. Und dass dieses so leicht geschehen kann, dass das in dem ersten Abschnitte des Processes gebildete Oxydsalz in mehreren Fällen - besonders da, wo das resultirende Quecksilberoxydulsalz löslich ist und deshalb nicht den Verlauf der Reaction hemmt nicht nachzuweisen ist, beruht auf dem ganz ausserordentlich fein vertheiltem Zustande des freien Quecksilbers. Wenn man z. B. eine Lösung von salpetersaurem Quecksilberoxydul mit Natronlauge versetzt, und gleich danach den entstandenen Niederschlag, von welchem wir jetzt wissen, dass er Quecksilber und Quecksilberoxyd enthält, in schwacher Salpetersäure löst, so crhält man eine Lösung, die, nachdem das Quecksilberoxydul mittelst Salzsäure gefällt und abfiltrirt worden ist, mit Schwefelwasserstoff nur eine sehr schwache, bräunliche Farbe annimmt, also nur eine Spur von Quecksilberoxyd enthält, gewiss nicht mehr, als in dem 
besprochenem Salze gewöhnlich als Verunreinigung vorauszusehen ist. Ist dagegen das resultirende Quecksilberoxydulsalz schwer löslich und ist der Niederschlag nicht mit viel Wasser gemischt, so schreitet die Reaction nicht so schnell voran, weil das neue Salz, welches in diesem Falle zum Theil in festem Zustande auftritt, einen Theil des Niederschlages einhüllt und also das Quecksilber gegen das entstandene, sich in Lösung befindende Oxydsalz schützt. In dem dritten Falle endlich, dass das Oxydulsalz unlöslich ist, verläuft die Reaction aus denselben Ursachen noch langsamer und schwieriger. Hieraus erklärt es sich, warum das in dem Niederschlage vorhandene Quecksilberoxyd nicht durch Salpetersäure, und nur unvollkommen durch Essigsäure und Schwefelsäure, dagegen wie oben erwähnt, leicht und deutlịch mittelst Salzsäure nachzuweisen ist. Bei der Verwendung dieser Säure sieht man auch recht deutlich, wie gross die Bedeutung der Vertheilung des Quecksilbers bei allen diesen Versuchen ist. Behandelt man nämlich einen Theil des Niederschlages in ganz frischem Zustande, einen anderen Theil nach Abtrocknen zwischen Fliesspapier, wobei sich also das Quecksilber etwas gesammelt hat, mit Salzsäure, dann wird es ungleich lange Zeit dauern, bis die weisse Farbe des Quecksilberchlorürs in den beiden Versuchen deutlich hervortritt; in der ersten Mischung kann dieselbe beim fleissigen Schütteln schon nach einigen Minuten erscheinen, in der zweiten erst nach mehreren Stunden. Nach dem Gesagten wird man auch verstehen, dass der getrocknete Niederschlag, welcher von Guibourt untersucht wurde, und worin das Quecksilber unter der Lupe sichtbar war, diesem eine Lösung von Quecksilberchlorid geben konnte. Es wird aber auch ersichtlich sein, dass die Bedingung hierfür die gewesen ist, wie ich schon S. 447 angegeben habe, dass ein Theil des Quecksilbers unverändert geblieben ist; denn wenn $\mathrm{Hg}$ und $\mathrm{HgO}$ in dem Verhältnisse der Molekulargewichte gemischt sind (das Verhältniss muss nothwendiger Weise dieses sein, wenn von reinem Quecksilberuxydulsalze ausgegangen wurde), dann muss die Salzsäure, um $\mathrm{Hg}_{2} \mathrm{Cl}_{2}$ zu bilden, die beiden Stoffe eben in diesem VerJournal f. prakt. Uhemie [8] Bd. 38. 
hältnisse aufnebmen, es kann also kein $\mathrm{HgCl}_{2}$ vorhanten sein, wenn nicht freies Quecksilber anwesend ist. Alles dieses giebt aber nur Auskunft über die Anwesenheit von Quecksilber und Quecksilberoxyd im Niederschlage; von dem möglichen Gehalte an Quecksilberoxydul erfahren wir dabei ganz und gar nichts.

Mittlerweile hatte ich eine Beobachtung anderer Art gemacht, und indem ich diese zu deuten suchte, kam ich dazu, einen Weg einzuschlagen, der mich endlich zum Ziel brachte.

Es war mir nämlich aufgefallen, dass beim Hinstellen des Niederschlages einige Theilchen desselben nach einem oder zwei Tagen ganz gelb geworden waren Dies bemerkte ich zuerst bei einzelnen Flocken, die beim Auswaschen des Niederschlages an den Seitenwänden des Glases hängen geblieben waren oder auf' der Oberfläche der Flüssigkeit schwammen, und ich überzeugte mich bald, dass die gelbe Farbe nur da hervortrat, wo die Luft freien Zutritt fand, übrigens aber ebenso leicht im Dunkeln wie im Lichte; unter Wasser blieb der Niederschlag immer dunkel. ${ }^{1}$ ) Es konnte also nicht bezweifelt werden, dass die gelbe Substanz Quecksilberoxyd wäre; um dieselbe aber zu prüfen und eine dentliche Vorstellung darüber zu gewinnen, wie schnell die Aenderung fortschreitet, wurde der frische, bloss ausgewaschene Niederschlag mittelst eines Glasstabes ganz düm auf Glasplatten gestrichen und in einem dunkeln Schranke der Luft ausgesetzt. Das Resultat war immer das nämliche; nach einigen Tagen war ein schmaler, hellgelber Strich längs der Peripherie zu sehen, doch war der innere Theil jetzt auch etwas weniger dunkel geworden. Während der nächsten Tage breitete sich die gelbe Farbe gleichmässig weiter nach nnen aus; die letzten dunkeln Flocken verschwanden erst. nach 3 oder 4 Wochen. Die gelbe Substanz wurde danach losgelöst und mit schwacher Salzsäure geprüft; sie löste sich vollständig ohne Aufbrausen oder hinterliess nur eine ganz kleine Menge Quecksilberchlorür, welche von einer kleinen,

1) Vergl. jedoch die Aumerk. S. 463, Zusatz 1888. 
durch die Luft unveränderten Menge des ursprünglichen Niederschlages herrühren konnte. Dieser ungelöste Rückstand war so klein, dass die Flüssigkeit ohne Filtration mit Ammoniak einen weissen, mit Jodkalium einen rothen Niederschlag u. s. w. gab.

Zur Erklärung dieser Umbildung ist es wohl am einfitchsten, anzunehmen, dass der Niederschlag nur ein Gemisch aus Qnecksilber und Quecksilberoxyd ist, und damit steht seine Farbe auch nicht in Widerspruch. ${ }^{1}$ ) Die ganze

1) Um die Farbe solcher Mischungen init derjenigen des Niederschlages vergleichen zu könuen, habe ich Quecksilber und gelbes Quecksilberoxyd in verschiedenen Verhältnissen zusammengerieben, und da ich dabei einige andere Beobachtungen gemacht habe, welche hemerkenswerth erscheinen, werde ich die Gelegenheit benntzen, dieselben hier mitzutheilen. Werden nămlich ungefähr gleiche Theile ter beiten Stoffe in einem Porzellanmörser sorgfältig gemischt, eine Arbeit, die übrigens selbst bei kleinen Mengen (ein paar Gramm) mehrere Stunden dauert, dann erhält man ein pulverförmiges Gemiseh von einer dunkeln Farbe, welche derjenigen des Niederschlages recht ähnlich ist. Fügt man jetzt zu diesem Pulver ungefähr dreimal sovjel Quecksilber wie ursprünglich angewandt und setzt das Reiben hinlänglich lange fort, so wird das Gemisch nach und nach klumpig weich und zähe, wie fettig und salbenähnlich, mit bleigrauer Farbe metallglänzend und klebt an Mörser und Pistill, so dass diese ganz blank werden. Wird ein Theil der blanken Masse mittelst eines Glasstabes aufgescharrt, so bildet er einen matten, weichen Klumpen, der durch Druck wieder metallglänzend wird (s. unten). Wird aufs neue Quecksilber zugegossen, befeuchtet dieses gleich durch Adhäsion die blanken Scitenwände des Mörsers und was auf dem Boden desselben bleibt, 'rhält dadurch, dass eine kleine Menge des dunkeln Pulvers sich darauf legt, eine wirklich überraschende Aehnlichkeit mit einer wässrigen Wlüssigkeit, die einen Niederschlag enthält. Wenn man jetzt wieder das Ganze zusammenmiseht, und etwas davon in eine flache Porzellanschale bringt, so hat man eine beinahe ebenso leicht laufende und gläuzende Quecksilberkugel wie sonst, lässt man aber dieselbe einige Mal hin- und herlaufen, oder stösst man nun die Schale leicht ein Paar Mal gegen den Tisch, so verliert die Kugel ihren Glanz und hiillt sich nach und nach in ein schwarzes Pulver ein, welches sie der Beweglichkeit und der Kugelform beraubt; sie rollt nur schwer, wenn inan die Schale neigt. Durch einen leisen Druck mit dem Finger kam man aber wieder eine glänzende, leichtbewegliche Kugel aus dieser schwarzen Hülle herausbringen, sie zeigt aber, wenn sie in Bewegung gesetzt wird, dasselbe Verbalten wie die ursprügliche: sie 
Aenderung würde daan nur darin bestehen, dass das freio Quecksilber unter Zurücklassen des Quecksilberoxyds ver-

wird matt, schwarz, schwerrollend $u$. s. w. und alles dies kam oft wiederholt werden, bis sich die Kugel wir gewöhnliches Quecksilber verhält. Auffallend ist auch die Leichtigkeit, womit dio blauke Kugel in ihre schwarze Hülle zurückgleitet und dadurch ilır finheres Aussehen anniunmt. Das schwarze Pulver, welches sich so ansscheillut, ist ein Gemisch aus Quecksilber und Quecksilberoxyd; indem das Quecksilber verdunstet oder sich nach und nach sammelt, wird es beim Liegen gelb.

Was die Form betrifit, in welcher eine so bedeutende Menge Quecksilberoxyd (gewiss viel Mal mehr als gelegentlich von anderen Forschern bemerkt, z. B. Mohr bei der Darstellung von Quecksilbur durch Erhitzen von rothem Quecksilberoxyd: Gmelin, Handbuch dre Chemie 3, S. 740) in dem Quecksilber enthalten sein kann, so muss die Torstellung, dass dasselbe einfach gelöst sein solle, der Thatsachı: yegenüber, dass das Oxyd sich durch blosses Bewegen der Masse galı\% allmiahlich absetzt, aufgeben werden, und man wird zu der Amahnu' geführt, dass es bloss darin vertheilt ist, ganz wie es andere pulverförmigc: Körper in anderen Flüssigkeiten sein können. Dabei ist es aber wieder rent auffallend, dass das Oxyd sich nicht in der Ruhe freiwillig absetzt; selbst nach Monateı kann es beim Druck wieder glänzende liugeln geben, welche wieder matt, schwarz, schwerflüssig u. s, w werden, sobald wan sie in Bewegung setzt. Ich kann mir dieses nur 'lurch die Annahme erklären, dass die innere Beweglichkeit im flüssigen Quecksilber sehr gering, sowie der Unterschied zwischen den spucifischen Gewichten des Quecksilbers und des Quecksilberoxyds zu klein ist, als dass die Theilchen des letzteren diejenigen des ersteren verdrängen könnten.

Auch Quecksilberjodid, oder vielmelır das Jodür, kann mit Quecksilber einer solche weiche, salbenähnliche und glänzende Mischung geben. Werden Quecksilber und Quecksilberjodid nach dem Gewichtsverhältnisse $200: 454$ zusammengerieben, so erhält man bekanntlich das Jodür; durch Zusatz von mehr Quecksilber und anhaltendes Verreiben wird daun nuch unvl nach auf den Wänden der Reibschale eine spiegelblanke Sehicht und ınit noch mehr Quecksilber ein flüssiges Gemisch gebildet, welches in Aussehen u. B. w. ganz dem oben beschriebenen Quecksilberoxydgemische ahnlich ist.

Noch füge ich hinzu, dass auch andere schwere Metalloxyde, besonders Bleioxyd, durch langes Zusammenruben mit Quecksilber von diesem aufgenommen werden kömmen. Dies geschieht wohl nicht in dem Umfange wie oben, das Quecksilber vermag aber duch so viel Bleioxyd aufzumehmen, dass es durch Hin- und Herrolten in einer fiachen Schale den Flanz und die leichte Beweglichkeit verliert, matt schwarz, schwer 
dunstet. Nehmen wir aber an, dass der Niederschlag auch Quecksilbernxydul enthält, so muss die Aenderung gleichzeitig darin bestehen, dass das Oxydul sich entweder in Qnecksilber und Quecksilheroxyd spaltet, oder an der luft in Oxyd übergeht. Im Folgenden wird nachgewiesen werden, dass die erste Annahme, diejenige von Guibourt, ganz unhaltbar ist. Dies geht, wie vorläufig S. 442 angeleutet wurde, aus dem specifischen Gewichte des Niederschlages, viel deutlicher aber aus der Gewichtsänderung und dem sonstigen Verhalten des Niederschlages an der atmosphärischen Luft hervor.

Das specifische Gewicht ist nämlich kleiner, als für ein Gemisch von Quecksilber und Quecksilberoxyd anzunehmen ist. Da die älteren Bestimmungen des specifischen Gewichtes ziemlich stark von einander abweichen (s. S. 442), so habe ich selbst eine Bestimmung mit dem frischen, also durch Trocknen nicht veränderten Niederschlage ausgeführt. Ich ging

rollend wird u. s. w. Ein solehes Gemisch kann auch lange stehen, ohne dass die Oxyde sich absetzen. Es ist hieraus ersichtlich, dass die "fremden Metalle", welche im gewöhnlichen, nicht besonders gereinigten Quecksilher enthalten sind, sebr wohl in diesem als Oxyde vorhanden sein können, und dass das wohlbekannte quecksilberbaltige Pulver, welches mit der Zeit das Quecksilber wie staubig macht, aus dieser Quelle herrühren kann, ohno dass der Sauerstoff der Luft irgend welchen Antheil daran hat. Uebrigens geht anch aus dem Voraugehenden hervor, duss Quecksilber matt und schwarz werden kann, ohne solche fremde Metalle zu enthalten. Die Aenderung kann vom Quecksilberoxyd allein herrühren, und bierdurch wird ohne Zweifel oft die Abscheidung von dunklem Pulver in Barometern und ähnlichen Instrumenten bedingt, selbst bei Anwendung von destillirtem oder filtrirtem Quecksilber. Denn das Quecksilber kann durch Destillation wohl von fremden, nicht flüchtigen Metallen, getremt, dagegen nicht mit Sieherheit oxydfrei exhalten werden; seine Jämpfe können sich an der Luft oxydiren, und das entstandene Oxyd kano vom Quecksilber anfgenommen werden. Es wird auf diese Weise auch leicht begreiflich, dass Quecksilber in zugeschmolzenen Glasröhren, selbst wenn diese luftfrei sind, matt und dunkel werden kann. Um es so vollständig wite möglich zu reinigen, muss es nach der Destillation sehr lange und unter fleissigem Schütteln mit einer dazu gecigueten verdünnten Sïure, wio z. 13. Essigsüure oder Schwefelgz̈ure behandelt, danach mit Wasser ausgewaschen werden $u$. s. w. 
dabei so zu Werke, dass ich eine reichliche aber willkürliche Menge (ca. $10 \mathrm{Grm}$.) des bloss ausgewaschenen Niederschlages in eine solche Flasche, wie sie gewöhnlich für derartige Bestimmungen angewandt wird, brachte, dieselhe mit Wasser füllte und wog; danach wurde der Niederschlag in eine gewogene Schale gebracht, im Vacuum über Schwefelsäure bis zu constantem Gewichte getrocknet u. s. w. Sei es nun auch, dass etwa vorhandenes Quecksilberoxydul sich während dieser Arbeiten in Metall und Oxyd gespalten hätte, das Gewicht der Produkte müsste doch - unter der jedenfalls berechtigten Voraussetzung, dass wir es nicht mit Hydraten, die bei gewöhnlicher Temperatur in Anhydride übergehen, zu thun haben - dasselbe sein, als ob keine Zerlegung stattgefunden hätte, und das spec. Gew. wie gewöhnlich aus den Wägungen zu berechnen seill. Zwei solcher Versuche gaben 11,13, resp. 11,22, also ein etwas höheres spec. Gew. als früher gefunden, was gewiss seine Ursache darin hat, dass der Körper hier während der Wägung im Wasser ganz luftfrei war. Wäre der Niederschlag dagegen nichts als ein Gemisch von 200 Gew.-Thln. Quecksilber mit 216 Gew.-Thln. Quecksilberoxyd, so hütte sein spec. Gew. 12,14 sein müssen. Um diese Zahl berechnen zu können, habe ich auf die oben beschriebene Weise das spec. Gew. des ausgewaschenen, nicht aber getrockneten gelben Quecksilberoxyds bestimmt, denn als solches müsste das Oxyd hier vorbanden sein. Ich fand für dasselbe 11,05, ungefähr dasselbe, als von Anderen für das rothe Oxyd gefunden worden ist $(11,00-11,29)$. Vergleichen wir die höchste der gefundenen Zahlen 11,2 mit der berechneten 12,14, so ist es deutlich, dass der Niederschlag kein Gemisch von Quecksilber und Quecksilberoxyd allein sein kann.

$W$ as demnächst die Gewichtsänderung des Niederschlages bei Luftzutritt anlangt, so müsste er, wenn er aus 200 Gew.Thln. Quecksilber und 216 Gew.-Thln. Oxyd bestände, beim Verdunsten des ersteren $51,9 \%{ }^{1}$ ) des letzteren und immer

1) Es ist vielleicht nicht überfü̈ssig hervorzuheben, dass, selbst wenn der Niederschlag immer nur 51,9 \% Quecksilberoxyd hinterliesse, dies doch kein Beweis lafür sein würde, dass er ausser Quecksilber 
gleich viel hinterlassen, wenn die Temperatur nicht so hoch wäre, dass das Oxyd sich dabei zersetze und verflüchtige; er hinterlässt aber melr als $51,9 \%$ und nicht immer gleich viel. Drei Versuchen, bei welchen der bloss ausgewaschene Niederschlag in dünner Schichte auf dem Boden und den Seitenwänden gewogener Decantirgläser ausgebreitet wurde, die nach Trocknen und wiederholter Wägung offen in einen dunkeln und gut ventilirten Raum des Dampfapparates gestellt wurden, bis der Inbalt rein gelb und von constantem Gewichte war, gaben gegen $60 \%-70 \%$ Verdunstungsrückstand, was schon zeigt, dass das Mischungsverhältniss im Niederschlage nicht immer dasselbe ist. Es wurde Wärme angewandt, weil die Aenderung auf diese Weise ziemlich schnell verläuft, so dass der Versuch bei einer Stoffimenge von einigen Decigrammen nach einem oder zwei Tagen zu Ende war, und weil es vorerst nur darauf ankam, zu erfahren, ob der Rückstand 51,9\% oder wesentlich mehr betrug. Der aus diesem Versuche zu ziehende Schluss ist, dass der Niederschlag neben den beiden, schon nachgewiesen Bestandtheilen noch einen dritten enthalten muss. Es kann dies nur Quecksilberoxydul sein, und da der gelbe Rest bei Prüfung mit Salzsäure auf die oben (S. 450) erwähnte Weise sich, wie daselbst angeführt, verhielt, d. h. sich grösstentheils als Quecksilberchlorid löste und nur eine geringe Menge Chlorür hinterliess, so musste das Oxydul in die böher oxydirte Stufe übergegangen sein. Dass eine geringe Menge desselben der Oxydation entgangen war, kann unter den obwaltenden Um. ständen nicht überraschen (vergl. auch S. 468).

Um grössere Gewissheit darüber zu erhalten, dass der Niederschlag in der That Sauerstoff aus der Luft aufnehmen kann, habe ich folgenden Versuch angestellt. In einem Kolben mit langem und engem Halse wurde eine Probe des ausgewaschenen Niederschlages in dickem, breiähnlichem Zustande über den ganzen breitesten Theil desselben

nur Oxyd enthält; es würde dies sogar sehr gut mit der allgemeinen Vorstellung übereinstimmen, dass das Quecksilberoxydul leicht in Quecksilber und Quecksilberoxyd übergeht. Inwiefern eine solche Zerlegung iberbaupt anzunehmen ist, siehe $\mathrm{S} .470 \mathrm{ff}$. 
ausgebreitet. Nach kurzem Stehen mit dem Halse nach unten, damit das iiberflüssige Wasser ablanfen konnte, wurde der Kolben so in ein Cylinderglas mit Quecksilber gebracht, dass seine Oeffinung gespert war. In dem Kolbenhalce sammelte sich nach und wach anf dem Quecksilber einc etwa $2 \mathrm{Cm}$. hohe Schicht von noch herunterlaufenden Wasser. Das Ganze wurde, $n \mathrm{~m}$ gegen Ijicht geschützt zu sein, mit einem Blechmantel umgeben. Druck und 'l'emperatur beim Anfang des Versuches (Semptember 1882) wurden notirt. Schon in den nächsten Tagen war dentlich eine Luftaufnahme bemerkbar, und während der folgendon Zeit stieg das Quecksilber in dem Kolbenhalse so horh, dass ich hin und wieder Quecksilber in das Cylinderglis: nachfüllen musste. Nach 4 Wochen schien die Steigung aufgehört zu haben. Der Niederschlag hatte dann einen etwas helleren Ton angenommen, seine Farbe erinnerte an diejenige des Quecksilberjodürs, war aher dorh dunkler. Nacll weiteren 14 Tagen wurde die uibriggebliebene Isuft in rin eingetheiltes Glas übergeführt, gemessen und geprüt. Sir betrug $416 \mathrm{Ccm}$. und ein brennender Körper erlosch sofort in derselben. Der Kolben hatte ursprünglich $516 \mathrm{G} / \mathrm{cm}$. atmosphärische Luft enthalten; es waren also 19,4\% ocler. mit anderen Worten beinahe die ganze Sauerstoffmenge verbrancht worden. Ein kleiner Theil des Niederschlages wurde mit schwacher, kalter Salzsäure behandelt, bis das Ungelïste beinahe ganz weiss war und gab dabei eine lösung, dir eine reichliche Menge Quecksilberchlorid enthielt, ein Beweis dafür, dass der Sauerstoff wirklich zur Oxydation des Quecksilberoxyduls verwendet war. Der übrige Theil des Niederschlages wurde gesammelt, getrocknet und gewogen. Aus der gefundenen Yahl wurde das Gewicht der ganzen Menge des Niederschlages auf etwa 6 Grm. geschätzt, und da $100 \mathrm{Ccm}$. Sauerstoff nur 3,2; Grm. Quecksilberoxydul zu Oxyd oxydiren können, so ist nichts Auffallendes darin, dass die Farbe des: Niederschlages während des Versuches nur wenig bello! wurde. $\left.{ }^{1}\right)$

1) Zu'satz 1888. Neuerdings haben Brums u. von ler l'fordten mitgetheilt, dass $\vec{a}$ sie ebentalls gefunden'haben, dass sin solcher Nieder- 
Dass die Kohlensäure nicht bei der Umbildung des Niederschlages bei Luftzutritt hetheiligt ist, vielmehr derselben entgegenwirkt, geht aus dem folgenden Versuche hervor. Der frische, bloss ausgewaschene Niederschlag wurte auf einen Glasstreifen (liier und bei ähnlichen Versuchen wurden solche von ca. $20 \mathrm{Ctm}$. Länge und $4 \mathrm{Ctm}$. Breite benutzt) dünn aufgetragen. Der Glasstreifen wurde mittelst eines Fadens in eine 3 Lit.-Flasche hineingehängt, welche neben einem Gemisch von atmosphärischer Luft und Kohlensäure etwas Wasser enthielt, dimit der Niederschlag nicht zu schnell eintrockne. Die Flasche wurde im Dunkeln bei gewöhnlicher Temperatur hingestellt. Am rïchsten Tage hatte. der Niederschllag, obgleich er noch etwas dunkel war, einen gelbweissen Farbenton, was die Bildung von kohlensaurem Quecksilberoxydul andeutet, angenommen; nachdem der Niederschlag noch 14 Tige olne weitere Aenderung in der fllasche geblieben war, wurde er herausgenommen und im Dunkeln aufbewahrt; selbst nach einigen Monaten war das Aussehen des Niederschlages das gleiche, und nichts dentete darauf hin, dass eine limsetzming des kohlensauren Quec:ksilberoxyduls in Oxyd stattgefunden hatte. Es wird lieraus wuch verständlich, dass, wenn auch der Niederschlag beim '/utritt der freien Luft grösstentheils in Quecksilberoxyd umgebildet wird, es doch zur Bildnng einer kleinen Menge kohlensauren Quecksilberoxyduls kommen kann. Dieses Carbonat kanı wegen seiner kleinen Menge zwar keinen Eiuftuss auf die l'arbe ausüben, giebt sich anch kaum ‘lurch A ufhransen beim Lösen in Salzsüure zu erkennen, varmag aber doch bei dieser Gelegenheit die Bildung einer erkennbaren Menge Quecksilbexchlorürs zu verursachen (vergl. S. 450 ).

Wie es demnach zu erwarten war, so verlielt sich der Niederschlag im Wesentlichen in kohlensïurefreier und in gewöbnlicher atmosplürischer luft gleich. Es wurlen zwei Glasstreifen ganz wie oben in zwei $: 3$ Lit.-Flaschen hisr.ju-

schlag in der Juft an Gewidht zouimunt, und dass cliss durch die Oxydation des (quecksilberoxyduls veranlasst sein miïsse. Ber. 1Shs, 2010. 
gehängt; die eino enthielt etwas Natronlauge, die andere, damit die Luft in den beiden Flaschen gleich feucht bliebe, eine kleine Menge Wasser. Beide Niederschläge blieben im Dunkeln und hatten nach 14 Tagen nur den oben erwähnten grünlichen Ton angenommen. Jetzt wurden die Glasstreifen herausgenommen und in einen dunkeln Schrank gestellt; wic sonst fingen die beiden Niederschläge bald an, an den Kanten gelb zu werden, und nach weiteren 14 Tagen waren sie ganz hellgelb.

Bei diesen Versuchen musste es aber gleich auffallend erscheinen, dass die Niederschläge ihre dunkle Farbe beibehielten, so lange sie sich noch in den Flaschen befanden, bald aber anfingen gelb zu werden, wemn sie aus denselben herausgenommen wurden. Jede Probe betrug nur ca. 0,1 Grm. und die Flaschen enthielten also viel Mal mehr Sauerstof als zur vollständigen Oxydation derselben nöthig war, ja bei anderen ähnlichen Versuchen, wo die Menge des angewandten Niederschlages nach und nach auf $0,5 \mathrm{Mg} \cdot \mathrm{m}$. herabgeset $z$ t wurde, waren die Resultate ganz dieselben. In der Flasche blieb der kleine Fleck monatelang dunkel, nicht einmal am Rande desselben war etwas Gelbes zu sehen; aus der Flasche? genommen war er dagegen schon am nächsten Tage gell. Alles dieses stimmt aber mit dem, was ich oben nachgewiesen liabe, nämlich dass der Niederschlag freies Quecksilber enthält, überein. In dem abgesperrten Raume der Flasche kann das Quecksilber nur in ganz geringem Masse verdunsten, und der Niederschlag muss deswegen die dunkle Farbe, welche einer Mischung von Quecksilber und Quecksilberoxyd zukommt, behalten (siehe S. 451 Anm.). Erst wenn nur einige wenige Flocken des Niederschlages benutzt wurden, wurde er schon in der Flasche gelb oder gelblichweiss (Quecksilberoxyd oder kohlensaures Quecksilberoxydul) d. h. erst dann konnte er der darin befindlichen Luft alles Quecksilber abgeben. Hieraus ist zugleich ersichtlich, was für die vorliegende Untersuchung von grosser Wichtigkeit ist, dass freies Quecksilber in dem fein vertheilten Zustande, worin es in unserem Niederschlage vorhanden ist, an der Luft bei gewöhnlicher Tem- 
peratur keiner Oxydation unterliegt. ${ }^{3}$ ) Wäre das Entgegengesetzte der Fall - und es ist dabei gleichgültig, ob gleich Quecksilberoxyd oder zuerst Quecksilberoxydul gebildet würde, denn letzteres müsste alsbald in ersteres übergehen dann wäre es unerklärlich, dass 0,5 Mgrm. des Niederschlages, von welcher Menge wiederum nur eine geringe Menge (nach S. 467 kaum 0,1 Mgrm.) Quecksilber ist, mehrere Monate hindurch in 3 Lit. Luft dunkel bleiben kann, während es, der Luft ausgesetzt, bald gelb wird. ${ }^{2}$ )

1) Zusatz 1888. Noeh unwahrscheinlicher ist es dann, dass Queck. silber in dem gewöhnlichen gesammelten Zustancle einer Oxydation beim Stchen an der Luft bei gewöhnlicher Temperatur unterliegen sollte. Dafür hat sich in der neueren Zeit besonders Berthelot ausgesprochen und zwar dafür, das Quecksilberoxydul gebildet wird, indem er sich dærauf stützt, dass gereinigtes Quecksilber ein schwarzes Pulver absetzt, welches beim Behandeln mit Salzsäure Quecksilberchlorür bildet. (Compt. rend. (1880) 91,871.) Hierzu ist zu bemerken, dass, selbst bei der Verwendung von destillirtem, filtrirtem oder auf andere gewöhnliche Weise gereinigtem Quecksilber die Abscheidung eines solchen Pulvers nicltt als Beweis für eine stattgefundene Oxydation gelten kann, jedenfalls nicht dafür, dass eben Quecksilberoxydul entstanden ist; denn solches Quecksilber kann noeb Quecksilberoxyd enthalten und also auf rein mechanische Weise ein schwarzes Pulver absetzen (siehe S. 453 Anmerk.), welches ebenfalls mit Saizsăure Quecksilberchlorïr giebt, da es ein Gemisch von Quecksilber und Quecksilberoxyd ist (siehe \$. 448-450). Ich setze die Schwierigkeit, welche die Reinigung des Quecksilbers in dieser Hinsicht darbietet, mit dem Mangel an innerer Beweglichkeit, worauf ich schon oben aufmerksam gemacht habe, in Verbindung.

?) Nach Regnaults Bestimmung der Tension des Quecksilberdampfes und einer darauf gegründeten Berechnung enthält ein Liter bei $20^{\circ}$ mit Quecksilberdämpfen gesättigter Luft $0,41 \mathrm{Mgrm}$. Quecksilber. Wenn diese Zahl richtig ist, dann versteht man schwerlich, dass 3 Lit. Luft, welche also sollten 1,23 Mgrm. anfnehmen können, in drei Monaten nicht in Stande waren, $0,1 \mathrm{Mgrm}$. aufzunehmen. Es licgt gewiss nahe, anzunehmen, dass dieses darin seine Ursache hat, dass Quecksilber so langsam und in so geringer Menge verdunstet, dass selbst drei Monate für diese kleine Menge eine zu kurze Zeit gewesen ist; ich muss aber doch auf die unten zu besprechenden Versuche hinweisen, welche zeigen, dass es schnell genug verdunstet, urn nach 10 Minuten nachgewiesen werden zu können (S. 462) und dass 0,5 Mgru. von dem in 0,532 Grm. Niederschlag enthalteneı Quecksilber innerhalb 24 Stunden in 3 Lit. Luft bei gewöhnlicher Tempe- 
IV. Sowohl hier als melnmals im Vorangehenden habe ich es als selbstverständlich vorausgesetzt, dass das Hervortreten der gelben Farbe bei Luftzutritt auf der Vordunstung des freien Quecksilbers beruht und nach allem, was ich schon mitgetheilt habe, wird wohl schwerlich etwas dagegen sinzuwenden sein. Es schien mir aber doch zur vollständigen experimentellen Lösung der Aufgabe nöthig, das so verdunstete Quecksilber aufzufangen und nachzuweisen. Dieses schien mir lange Zeit hindurch nicht gelingen zu wollen. Ich liess z. B. 10 Tage lang von Morgen bis Abend mittelst der $W$ asserluftpumpe atmosphärische Luft durch eine $35 \mathrm{Cm}$. lange und $5 \mathrm{Cm}$. weite Glasröhre, auf deren innerer Seite

ratur verdunsten kaun, wenn nur die eimnal gebildeten Dämpfe furtwährend hinweggeschafft werden können (S. 4(i7). Ob der Niederschlag dunkel bleiben oder gelb werden soll, liängt, wie aus dem S. 461, I angeführten Versuche ersichtlich, davon ab, ob die I iimpfe vorhanden hleib'n oder entferat werden. Noch führe ith einen Versuch an, der beweist, dass der schon gebildete Quecksilberdampf die weitere $\mathrm{Ver}$ lunstung des Quecksilbers hindert, obwohl die den Regnault'schu'n Tahlen entsprechende sättigung noch lange nicht erreicht ist. Ein 25 Ctm. langer Glasstreifen, auf dessen einem Ende ich einen scliwacheu Quecksilberbeschlag dadurch hervorgehracht hatte, dass jch ih. uiber das erbitate Metall hielt, wurde in einer 3 Lit.-Flasche mit dem berehlagenen lnde nach oben angebracht. Der Beschlag wog kaum 0,; Mgrm. und sollte also nach Regnault von $1^{1 / 2}$ Lit. Iuft aufgenommen werden kömen; nach 41/2 nouatichem Strhen bei gewölntlicher 'lemperatur war aine Verkleinurung desselben weder zu se'heu noch mittelst der Wage nachzuweisen. Als aber eine Schale nit (iolitchloridlösung in dex Flasche neben dem Glasstreifen angebracht wurde. lauerte es nicht lange, bis die N. 461 u. f. besprochene Reduction des Givdes sich bemerkbar machte, d. h. die schon vorhandenen Dämpfe wurden absorbirt und gaben dadurch für eine neue Menge desselbe'n Raum, Jex Beschlag verschwand auch jetzt deutlich aber langsam, so dass die Verdunstung leinahe 3 Wochen in Anspruch nahm, was vielleicht darin liegt, dass das Quecksilber hier weniger fein als in clem Niederschlage vertheilt ist und mit grösserer Adhïsion am Glası. hängt. Aus allem scheint aber hervorzugehen, dass dic atmosphisisclin. luft nicht so viel Queeksilberdampt, wie wn Regnault gefundin. aufnehmen kann. Neuerdings haben auch Hagen und Herz für di* Tension der Quecksilberdänpfe bei zo" einrll bedentend kleinemu Worth als Regnault gefunden. 
eine reichliche Menge des Niederschlages und in deren hinterstem Theile ein Goldblech so angebracht war, dass der Luftstrom denselben bestreichen musste, saugen; der dunkle Niederschlag wurde wie gewöhnlich gelb, auf dem Golde war aber nicht die geringste Andeutung einer Amalgamierung zu entdecken. In einer 3 Lit.-Flasche wurden zwei, mittelst einer Korkscheibe von einander getrennte Glasscheiben aufgehängt (S. 457), von denen eine auf der Aussenseite mit dem Niederschlage bestrichen war, während auf der anderen einige Goldblättchen mittelst Gummiwatsser lose angeklebt waren; die Flasche wurde danach beinahe 7 Wochen sich selbst überlassen; der Niederschlag blieb aber dunkel, und das Blattgold goldgelb, das Quecksillher hatte sich also nicht verflüchtigt und sich nicht mit dem Golde verbunden, war dagegen ruhig im Niederschlage geblieben. ${ }^{1}$ ) Was mit dem metallischen Golde nicht gelungen war, gelang aber überraschend leicht bei Verwendung seines Chlorides, indem eine wässrige Lösung desselben Quecksilberdämpfe absorbirt. ganz wie concentrirte Schwefelsäurc Wasserdämpfe absorbirt. Dabei wird das Goldchlorid unter Bildung von Quecksilberchlorid und metallischem Golde reducirt. Es kann das Salz als normales Chlorid oder als Goldchloridchlorwasserstoff benutzt werden, es darf abcr nicht Salpetersäure enthalteı, wenn es empfindlich sein soll (siehe Anmerkung S. 462). Ich benutzte gewöhnlich eine Lösung des normalen Salzes, welche ca. $1 \%$ Gold enthielt.

Einige Versuche werden zeigen, wie emptindlich dieses Reagens für Quecksilberdämpfe ist. 1. Fin Glasstreifen mit kaum 1 Mgrn. des Niederschlages wurde in einer 3 Lit.Flasche aufgehängt, und nach 12 Tagen, während welcher Zeit der kleine dunkle Fleck nur seine Farbe ins schwach

1) Mit Rücksicht auf die Angabe Faraday's, dass Blattgold amalgamirt wurde, wenn es zwei Mnnate in einer Flasche, deren Boden mit Quecksilber bedeckt war, uufgehängt wirde, füge ich noch bei, dass, als nach den Schluss des Versuehes dit Glasstreifen aus der Flasche herausgenommen wurden und also naher besichtigt worden konnten, auf dem Golde ein einziger ganz kleiner weisser Quecksilberfleck zu sehen war. 
Grünliche geändert hatte, wurden einige Cubikcentimeter Goldchloridlösung in die Flasche gegossen. Am zweiten Tage danach flossen kleine, goldglänzende Hïutchen auf der Flüssigkeit herum und der Fleck war dann auch gelb gewordeu. - 2. Ein kleines Becherglas mit blanken Quecksilber wurde in ein literglas gebracht; nach halbstündigem Stehen bei gewöhnlicher Temperatur wurde dasselbe helausgenommen und durch einen Porzellantiegel mit einigen Cubikcentimetern Goldchlorid ersetzt. Nach 10 Minuten trat das reducirte Gold als bläuliche Flecken und Streifen auf dem weissen Porzellan hervor. (Glas eignet sich wegen seiner Durchsichtigkeit nicht bei so feinen Reactionen.) - 3. Auf cine Glasplatte wurden zwei kleine $11 / 2 \mathrm{Cm}$. tiefe Porzellanschalen gestellt, die eine enthielt eine Kleinigkeit blankes Quecksilbers die andere Goldchlorid, und darüber eine Glasglocke von ${ }_{1 / 2}$ Lit. Volumen angebracht; 10 Minuten liachher waren blaue Flecken anf dem Porzellan zu sehen. Selbst die geringe Menge Quecksilberdämpfe, die bei gewöhnlicher 'Temperatur innerhalb weniger Minuten von 1:, Lit. Lult aufgenommen werden kann (siehe S. 460 Aum.), kann ilso durch Goldchlorid nachgewiesen werden.')

1) Folgende Beispiele von der Branchbarkeit des Goldehlorids als Reagens für Qnecksilberdämpfe theile ieh noch mit, da sie wohl verdienen bekaunt zu werden.

1. Dit Flüchtigkeit des Quecksilbers bei niedriger 'Temperatur kann nach der oben unter 2 erwähnten Methode nachgewiesen werden, wobei jedoch eine kleine Aenderung nöthig ist, damit die Goldehloridlüsumg nicht gefriere. Es wurde ein 3 Literglas (hier wie übtrall bei ähnlichen Versuchen mit. Glasstöpsel) in eine Kältemischung aus Kochsalz und Schnee gestellt, und, als nach dem Verlauf einer Stunde das (tarin angebrachte Thermometer $-8^{\circ}$ zeigte, ein kleines Becherglas unit ea. $50 \mathrm{Grm}$. blanken Quecksilbers darin angebracht. Nach weiteren 2 Stunden wurde lieses wieder herausgenommen; das Thermometer zeigte fortwahrend $--8^{\circ}$. Das grosse, jetzt also lere Glas, wurde alls der Kältemischung entfernt und ein Tiegel mit Goldchlorid in dasselbe gebracht. Nach $1 \%$ stiiudigem Stehen bei gewöhnlicher Temperatur waren bläuliche Flecken uni Streifen auf dom Porzellan zu sehen, ein Beweis dafür, dass die Iuft im Glase bei $-8^{\circ}$ Quecksilberdämpf? aufgenommen hatte. Der Versuch wurde mit demselben Resultat: wiederholt. 
Mittelst Goldchlorid gelingt es nun leicht, auf ähnliche Weise das entweichende Quecksilber nachzuweisen. Wie

2. Dass Quecksilber, welches mit Wasser bedeckt ist, dennoch Dämpfe an die umgebende Luft bei gewöhılicher Temperatur abgeben kann, habe ich auf verschiedene Weise nachgewiesen. In ein 3 Iiterglas, welchem ich: um leichter die Versuchsobjecte hineinbringen und herausnehmen zu können, eine liegende und feste Stellung gab, wurde zunächst ganz dicht am Boden ein Porzellantiegel mit einigen Cubik. centimetern normaler Goldchloridlösung gestellt. Nachdem das Glas so 12 Tage im Dunkeln gestanden hatte, während welcher Zeit nicht die geringste Spur von blauen oder ähnlichen Streifen auf dem Porzellan hervortrat, wurde eine Porzellansehale mit blankem Quecksilber und darüber stehendem Wasser in den vorderen Theil desselben gebracht und das geschlossene Glas wieder ins Dunkele gestellt. Das Quecksilber wog $50 \mathrm{Grm}$. und seine Oberfläche hatte einen Durehmesser von $3 \mathrm{Cm}$., das Wasser wog $15 \mathrm{Grm}$. und stand über dem Qulecksilber in einer Höhe von $1 \mathrm{Cm}$. Nach 3 Tagen war ein schwacher, bläulicher Ring auf dem Porzellan über der Goldlösung, da nämlich, wo die Flüssigkeit sich an der Tiegelwand aufwärts gekrümmt hatte, zu sehen. Dieser Ring nahm in der Folge gleichmässig zu, und als nach 14 Tagen bei dem Abseblusse des Versuchs der Tiegel herausgenommen und sein Inhalt näher untersucht wurde, waren auf der Flïssigkeit cine Menge ganz kleiner Goldhäutchen, aber bei richtiger Stellung des Auges direct sichtbar, und unter der lupe konnte man auch die blaue Abscheidung als aus solchen bestehend erkennen, nachdem sie nachher durch etwas Wasger von den Tiegelwänden losgelöst wurde. - Ich brauche wohl kaum zu bemerken, dass, wenn es auch bei diesem und anderen ähnlichen Versuchen, die unter Beobachtung aller Vorsichtsmassregeln angestellt sind, unbestreitbar ist, dass Quecksilber bei gewöhnlicher Temperatur durch eine Wasserschicht von ganz ansehnlieher Höhe verdunsten kann, seine Flüchtigkeit doch unter diesen Umständen viel geringer ist, als bei directem I.uftzutritt. Die bei einem solehen Versuche reducirte Goldmenge liegt deshalb auch weit unter dem Wägbaren, sie ist gewiss viel geringer als 1/1000 Mrrm., denn sie erscheint sehr klein neben einem Quadratmillimeter Blattgold, dessen Gewicht doch nur 0,0028 $\mathrm{Mgrm}$. beträgt.

Zusatz 1868. Es ist nach dem ohen Mitgetheilten verständlich, dass der schwarze Natronniederschlag durch sehr langes Aufbewabren unter Wasger in einem offenen Becherglase gelb werden kann; während das Quecksilberoxydul sich in Oxyd umsetzt, verdunstet das freie Quecksilber. Dass solches geschehen kann, goht aus einem im vorigen Jahre abgeschlossenen Versuch hervor, bei wolchem der Niederschlag unter Wasser in einem geschlossenen 3 I.it.-Glase in völliger Dunkelheit neben Goldchlorid 2 Jahre hindurch aufgestellt gewesen war. 
früher, wurde ein (xlasstreifen nit dem düun ausgebreitetu'u Niederschlage in eine 3 Lit.-Flasche hineingehängt; diese

Die Reduction der Goldlösung hielt fortwährend mit dern Gelbwerden des Niedersehlages gleichen Schritt.

3. Ich habe mich auch durch wiederholte Versuche davon überzenyt, dass die Zinnamalgambelegung der gewöhnlichen spiegel, selbst wenn diese sehr alt sind, Quecksilberdäinpfe abgiebt. Ieh brachto in cin 3 Lit.-Glas ein ca. 70 Quadratcentim. grosses Stück eines neueren Spiegels und einen Porzellantiegel mit Goldchlorid. Ein paar Stunden danach waren schon auf dem Porzellan bläuliche Flecken vorhanden, und einige Tage nachher flossen goldglänzende Häutchen auf der Flüssigkeit herum. Bei einem andern, zweimal so grusien Stück eines sehr alten Spiegels war erst 24 Stunden nach dem Anfange des Versuchs ein schwacher bläulicher Rand auf dem Tiegel zu bemerken. "r nahm aber wie gewöhnlich nach und nach zu, und als der Versuch nach 14 Tagen abgeschlossen wurde, war eine Nenge kleiner Goldhäutchen auf der Lösung wahrzunehmen.

Für alle solche Versuche sind Porzellantiegel besser geeignet alls Schalen, unter anderm auch deswegen, dass sie durch Ausglühen von mö̈rlichen Spuren organischer Substanz befreit werden können. Fs wurden ineist solche von $15 \mathrm{Ccm}$. Grösse verwendet. Auf ihren steilen blankeı Seiten ist der blaue Farbenton auch sehr deutlich wahrzunehmen. -.. In solchen Fällen, wo nur eine schwache Reaction zu erwarten ist. muss das Reagens mittelst einer surgfältig geromigten Pipette aus der Aufbewahrungsflasehe herausgenommen werden. Dasselbe direct aus der Flasehe zu griessen, ist micht zu lathen, da Staub und dergleich'n sich leicht auf die Mündung der Flasche absetzen kann. Selbst bei Beobachtung dieser Massregel, und selbst wenn der Tiegel augenblicklich und allein in das Versuchsglas gebracht wird, kaun man aber dennoch, allerdings seltever bei dem sauren als bei dem neutralen Goldsalze, nach 1 bis 2 Tagen einige ganz kleine Flocken, wic cin'n l'unkt oder einen kleinen Fleck mitten anf der Oberfläche der Fliissigkeit finden. Ich kann die Ursache hierzu nicht bestimmt angeben, da ich aber nichts derartiges bei dem Reagens bumerkt habe, so lange: es in der Aufbewahrungsflasehe war, so vermuthe ich, dass spuren voll organischen Substanzen in der Luft daran schuld sind, romn auch wenı die Gläser weit vom ILaboratorium entfernt, im Garten mit Luft geftillt wurden rder bei Verwendung des chlorwasserstoffsauren Salzes konnte sich diever Fleck bilden. Eine blane Ausscheidung, welche: immer die Form ist, in weleher sich dis: Reattion der Quecksilberdampfe zuerst benerkbar micht, habe ich bei den vielen Versuchen, welche ith anstellte, um dic Ursache der erwähnten Erscheinung zis crfahrem, niemals beobarhtet, und diese ist ausserdem so schwach und bleibt bei weiterem Stehen in Dunkeln stets so unverändert, dass sic: 
liess ich 10 Tage im Dunkeln und bei gewöhnlicher Tenıperatur stehen, tügte jetzt Goldchloridlösung hinzu und liess das Ganze unter denselben Umständen ruhig stehen. Am zweiten Tage hatte sowohl die Bildung eines gelben Ringes als die Reduction der Goldlösung angefangen, und nach 20 Tagen war die ganze Menge des Niederschlages gelb geworden, ganz als ob sie in der freien Luft geblieben wäre. Die Lösung wurde jetzt herausgespült, das überschüssige

zu Irrthümern bei den besprochenen Versuchen gar keine Veranlassung geben kann Ich erwähne dieselbe wesentlich nur, damit andere Chemiker, bei Wiederholung meiner Versuche, darauf aufmerksam geworden, nicht etwa glauben sollen, dass sie meiner Aufmerksamkeit entgangen wäre. Vorsichtiger Weise lässt man aber doch die Tiegel mit der Goldlösung einige Tage allein im Versuchsglase im Dunkeln stehen, ehe man die zn untersuchenden Objecte hineinbringt (s. z. B. oben 2). Glasglocken und äbuliche Geräthschaften, wo organische Stoffe als Vichtungsmaterial in Verwendung kommen, sind deswegen für diese Versuche nicht so zweckmässig wie Gläser mit eingeschliffenen Stöpseln.

Dass die erwähnten blauen Abscheidungen aus reducirtem Golde besteben, ist schon S. 463, Anm. 2 nachgewiesen, und geht auch daraus hervor, dass sie, wenn ihnen durch längeres Fortsetzen des Versuches Gelegenheit dazu geboten wird, dann bräunlichgelb bis gelb und metallglänzend werden; doch erinnere ich daran, dass man auch durch Reduction einer Goldlösung mittelst sehwefliger Säure oder Oxalsaure in einer Porzellanschale auf derselben blaue Absetzungen erhalten kann. Dass sie blau sind, obgleich sie bei auffallendem Lichte gesehen werden, erkläre ich dadurch, dass man, so lange sie so ausserordentlich dünı sind, durch dieselben die weisse, belle Porzellantläche sieht, und erst wenn sie dicht geworden sind, wird das Auge durch das von ihnen zurückgeworfene gelbe Licht beeinflusst. Ich bin deswegen auch der Meinung, dass Gold nur blaues Licht durchlässt, und dass die grünliche Farbe, welche man sieht, wenn Blattgold dicht vor das Auge gehalten wird, dadurch bedingt ist, dass man gleichzeitig Eindruck von den durcbgelassenen blauen and den gelben Strahlen, die von den dichteren Goldpartikeln reflectirt sind, erhält.

An dieser Stelle soll die Bemerkung Platz finden, dass auch Silbernitrat und Platinchloridlösungen Quecksilberdampf aus der umgebenden Luft absorbiren und dadurch Abscheidung von Silber, resp. Platin geben können. Ich brachte in ein 3 Lit.-Glas einen Glasstreifen mit einem schwachen Quecksilberbeschlag und cinen Porzellantiegel mit der betreffenden Lösung. Nach 2 Stunden hatten sich auf der Silberlösung kleine silberweisse und auf der Platinlöstung platingraue Häutchen gebildet.

Journal f. prakt. Chemie [2] Bd. $\$ 8$. 
Goldchlorid mittelst Oxalsäure reducirt, und das Filtrat mittelst Schwefelwasserstoff gefallt. Der dadurch erhaltene Niederschlag wurde wie gewöhnlich durch Erhitzen mit wasserfreiem Natriumcarbonat in einem Reagircylinder geprüft, wodurch eine sehr schöne Quecksilberreaction, sowohl Beschlag als Tropfen, erhalten wurde.

Hierdurch zeigte sich ein Weg für die directe quantitative Bestimmung des freien Quecksilbers und dadurch für die Berechnung der zwei übrigen Bestandtheile, des Oxyds and des Oxyduls; denn Quecksilber und Quecksilberoxyd müssen, da sie ursprünglich als Quecksilberoxydulsalz vorhanden waren, in dem Gewichtsverhältnisse 200:216 vorhanden sein; die Menge des Oxyds kann also aus derjenigen des freien Metalls berechnet werden. Wenn man dann das Gewicht entweder des in Arbeit genommenen Niederschlages oder des gelben Restes (d. b. die ganze Menge des Quecksilberoxyds nach der Oxydation an der Luft) und das Quecksilber bestimmt hat, welches wiederum auf zweierlei Weise geschehen kann, nämlich entweder durch die Menge des reducirten Groldes, indem die Umsetzung im Sinne der Gleichung:

$$
2 \mathrm{AuCl}_{3}+3 \mathrm{Hg}=2 \mathrm{Au}+3 \mathrm{HgCl}_{2}
$$

erfolgt, oder direct in dem nach der Ausscheidung des Goldes erhaltenen Filtrat, so hat man alle für die Berechnung des Oxyduls nöthigen Werthe - alles unter der Voraussetzung, dass das Quecksilberoxydul nicht bei gewöhnlicher Temperatur und im Dunkeln zerlegt wird. Ich habe zwei solcher Analysen von Niederschlägen aus verschiedenen Darstellungen ausgeführt.

A. Eine unbestimmte Menge des frischen, bloss ausgewaschenen Niederschlages wurde auf einem gewogenen Glasstreifen ausgestrichen und in die Flasche gebracht. Nachdem die Flasche einige Zeit wie gewöhnlich im Dunkeln und bei gewöhnlicher Temperatur sich selbst überlassen gewesen war, wurde Goldchlorid zugegeben. Als der Niederschlag nach neuem Hinstellen gelb geworden war, wog er 0,085 Grm. Das reducirte Gold betrug 0,0108 Grm. Das überschüssige Goldchlorid wurde mit Oxalsäure gefällt, 
abfiltrirt, und im Filtrate das Quecksilber mittelst $\mathrm{H}_{2} \mathrm{~S}$ als Sulfid gefällt. Dieses wog 0,0195 Grm.. 0,0168 Grm. Quecksilber entsprechend, was mit der gefundenen Goldmenge gut übereinstimmt, indem

$$
2 \mathrm{Au}: 3 \mathrm{Hg}=394: 600=0,0108: 0,01645 .
$$

Wenn man das reducirte Gold der Berechnung zu Grunde legt, so erhält man die folgenden Zahlen:

Freies Quecksilber, 0,0108 Grm. Gold ent-

sprechend. . . . . . . . . . . $0,01645 \mathrm{Grm}$, oder 16,6\% Quecksilberoxyd, 0,01645 Grm. freien

Quecksilbers entsprechend. . . . 0,0178 " "18,0 , Quecksilberoxydul, $0,085-0,0178=0,0672$

Grm. Quecksilberoxyd entsprechend $, \frac{0,0647}{0,09895 \mathrm{Grm} .}, \frac{\mathbf{6 5 , 4}}{\mathbf{1 0 0 , 0 0}}$,

Wird auf ähnliche Weise das direct gefundene Quecksilber der Berechnung zu Grunde gelegt, dann sind die Zahlen:

Freies Quecksilber . . . . . . . . 0,0168 Grm. oder 16,9 \% Quecksilberoxyd, 0,0168 Grm. freien Queck-

silbers entsprechend . . . . . . 0,0181 " " 18,2 " Quecksilberoxydul, $0,085-0,0181=0,0669$

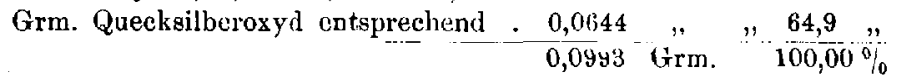

Das ursprünglich unbekannte Gewicht des in Arbeit genommenen Niederschlages war also, dem Durchschnitte der beiden Bestimmungen zufolge, 0,0991 Grm. Der gelbe Rest, der durch Luftzutritt erhalten war und der 0,085 Grm. wog, betrug also $85,8 \%$ (vergl. S. 455 ).

B. Um eine grössere Substanzmenge in Arbeit nehmen zu können, wurde der Niederschlag diesmal auf ein gewogenes Uhrglas gebracht. Ueber Schwefelsäure getrocknet, wog er 0,532 Grm. Ich liess denselben zuerst zur vorläufigen Oxydation einen Monat hindurch unter einer mit Wasser abgesperrten Glasglocke mit atmosphärischer Luft stehen; er nahm in dieser Zeit nicht unbeträchtlich an Gewicht zu, nämlich 0,01 Grm., und hätte wohl durch längeres Stehen noch mehr zugenommen. Darauf wurde das Uhrglas mit der Substanz auf einem Glasfusse in einer 
3 Lit. - Flasche, deren Boden mit Goldchlorid bedeckt war, aufgestellt. $\mathbf{N}_{\sharp}$ ch Verdunsten des Quecksilbers u. s. w., wozu 10 Wochen erforderlich waren, wog der gelbe Rest 0,494 Grm. $=92,9 \%$ (vergl. S. 455); dieser wurde mit verdünter, kalter Salzsäure gepriift und hinterliess nur $0,011 \mathrm{Grm}$. ungelösten Quecksilberchlorürs. Das reducirte Gold wog 0,0325 Grm. und das aus der Lösung gefällte Quecksilber betrug also 0,0487 Grm.

Wird das reducirte Gold der Berechnung zu Grunde gelegt, so erhält man:

Freies Quecksilber, 0,0325 Grm. Au ent-

sprechend . . . . . . . . 0,0495 Grm. oder $9,3 \%$ Queeksilberoxyd, 0,0495 Grm. Hg entspre-

chend . . . . . . . $0,0535, ", 10,06$,

Quecksilberoxydul, $0,532-(0,0495+0,0535)-\frac{0,429}{0,532}$ Grm. $"=\frac{80,64}{100,00} \%$

Indem man von dem direct bestimmten Quecksilber ausgeht, erhält man :

Freies Quecksilber . . . . . . . . 0,0487 Grm. oder 9,15\% Quecksilberoxyd, 0,0487 Grm. Hg entspr. 0,0526 " , 9,89 ",

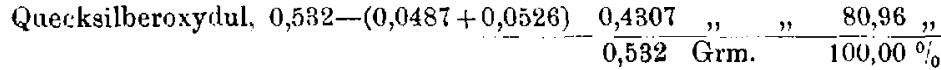

Als Durchschnitt der beiden Berechnungen findet man also, dass das Quecksilberoxyd 9,98\%, das Quecksilberoxydul $80,80 \%$ beträgt, was ganz gut damit übereinstimmt, dass der gelbe Rest $92,9 \%$ betrug; denn den 80,80 Gewichtstheilen Quecksilberoxydul entsprechen 83,91 Gewichtstheile Oxyd, und 100 Theile des Niederschlages sollten also nach der Oxydation des Oxyduls und Verdunstung des freien Quecksilbers 83,91 + 9,98=93,89 Gewichtstheile Quecksilberoxyd geben. Das Mischungsverhältniss der Bestandtheile wird also annähernd gleich gefunden, sei es dass man bei der Berechnung wie hier von dem Gewicht des angewandten Niederschlages oder von der Menge des gelben Restes ausgeht.

Diese Analyser zeigen, was schon S. 455 angedeutet ist, dass die näheren Umstände, unter denen der Niederschlag gebildet wird, Einfluss auf das Mischungsverhältniss seiner Bestandtheile ausüben müssen. Dieses haben wohl 
auch diejenigen Forscher gemeint, welche Methoden zur Darstellung des Quecksilberoxyduls angegeben haben, indem sie sich jedoch in dieser Binsicht nur darauf stätzten, dass der Niederschlag mehr oder weniger leicht durch Reibung Quecksilberkugeln geben konnte und mehr oder weniger löslich in Essigsäure und unlöslich in Salzsäure war. Solche Proben geben aber, was die quantitative Zusammensetzung betrifft, nur sehr wenig Auskunft; denn das Resultat hängt wesentlich davon ab, wie fein vertheilt das Quecksilber ist, und wie lange die betreffende Behandlung fortgesetzt wird. Durch dieselben kann man also nicht erwarten, zur Kenntniss der Umstände, welche die nähere Beschaffenheit des Niederschlages bestimmen, zu gelangen, und auch nicht zu erfahren, ob es überhaupt möglich ist, ein reines Quecksilberoxydul darzustellen. Dagegen erscheint es jetzt möglich, durch die oben angewiesenen Wege diese und mehrere andere Fragen, die Eigenschaften dieser Verbindung betreffend, zu beantworten. Von solchen hebe ich nur die noch offene Frage hervor, ob das Quecksilberoxydul ohne Zersetzung einer Temperatur von $100^{\circ}$ ausgesetzt werden kann, welche Frage nicht dadurch beantwortet ist, dass es, wie oben S. 455 nachgewiesen, bei dieser Temperatur löher oxydirt werden kann, denn es ist ja die Möglichkeit vorhanden, dass ein Theil desselben zersetzt, ein anderer Theil dagegen oxydirt wird. ${ }^{1}$ ) Dieses ist auch in der That der Fall; denn der gelbe Rest, das Oxyd, welches der Natronmiederschlag giebt, wenn er im Dunkeln bei $100^{\circ}$ der Luft ausgesetzt wird, ist kleiner, als wenn die Oxydation bei gewöhnlicher Temperatur stattfindet. Ich babe nicht wenige Versuche hierüber mit Niederschlägen von verschiedenen Darstellungen auf die Weise ausgeführt, dass ich einen Theil des Präparates, auf einer Glasplatte dünn ausgestrichen und nach dem Trocknen über Schwefelsäure gewogen, im Dunkeln bei Zimmertemperatur zur Oxydation liegen liess, während ein

1) Dafür, dass eine Zersetzung und eine Oxydation bei demselben Stoffe gleichzeitig stattfinden können, giebt uns das Kaliumchlorat ein wohlbekanntes Beispiel; beim Schmelzen desselben zersetzt sich ein Theil in Chlorkalium und Sanerstoff, während ein anderer Theil durch Oxydation in Hyperchlorat übergeht. 
anderer Theil desselben Niederschlags bei $100^{\circ}$ behandelt wurde, bis jeder Theil ganz gelb und die Gewichte constant geworden waren, was, wie früher erwähnt, bei gewöhnlicher Temperatur sehr langsam, bei $100^{\circ}$ dagegen ziemlich schnell geht (S. 450 und 455). Das Resultat war immer insofern das gleiche, als das gelbe bei $100^{\circ}$ erhaltene Residuum kleiner, als das bei Zimmertemperatur erhaltene war, und, was ich wieder hervorheben muss, mehr betrug, als wenn die ganze Menge des Quecksilberoxyduls zersetzt gewesen wäre, also mehr als $51,9 \%$ (S. 455 ). So gab z. B. ein aus salpetersaurem Quecksilberoxydul durch Zusatz von überschüssigem Natronhydrat dargestellter Niederschlag nach 24 stündigem Stehen bei $100^{\circ} 60,1 \%$ des gelben Produktes, dagegen bei 2 monatlichem Liegen bei gewöhnlicher Temperatur $71,3 \%$, und dieser letzte Rest wurde, als er nach dem Wägen 24 Stunden einer Temperatur von 100" ausgesetzt wurde, nur auf $70,4 \%$ reducirt. Die übrigen Versuche ergaben dasselbe, nur mit einem anderen, bald grösseren, bald kleineren Unterschiede zwischen den gefundenen Procenten, indem die Mischungsverhältnisse der verschiedenen Niederschläge hier zur Geltung kommen müssen. Alles dieses zeigt deutlich, dass der Niederschlag bei gewöhnlicher Temperatur eine solche Veränderung erleidet, dass Wärme danach keinen so grossen Einfluss wie auf den frischen Niederschlag ausübt, d. h. die Oxydation findet in grösserem Umfange als bei $100^{\circ}$ statt, und wie wir geschlossen haben, dass nicht alles Quecksilberoxydul bei $100^{\circ}$ zersetzt wird, da der gelbe Rest in diesem Falle nicht über $51,9 \%$ betragen könnte, so müssen wir andererseits auch schliessen, diss ein Theil desselben zersetzt wird; denn sonst müsste der gelbe, bei $100^{\circ}$ erhaltene Rest ebenso gross, als der bei gewöhnlicher Temperatur erhaltene, sein.

Aus den obigen Mittheilungen ergiebt sich folgendes:

1. Der Natronniederschlag der Quecksilberoxydulsalze ist nicht ein Gemisch von Quecksilber und Quecksilberoxyd allein (Gujbourt), sondern er besteht ursprünglich aus Quecksilberoxydul, Quecksilber und Quecksilberoxyd. Das 
Mischungsverhältniss ist ein sehr verschiedenes. Es sind bis gegen $81 \%$ Quecksilberoxydul in demselben gefunden worden.

2. Besagter Niederschlag wird, wenn er der atmosphärischen Luft bei gewöhnlicher Temperatur ausgesetzt wird, sowohl im Lichte als im Dunkeln oxydirt, indem das Quecksilberoxydul in Quecksilberoxyd übergeht. In abgesperrter Luft behält er dabei seine ursprüngliche dunkle Farbe, da das darin enthaltene Quecksilber, welches nicht verdunsten kann, die helle Farbe des Quecksilberoxyds deckt. Bei ungehindertem Zutritt der Luft wird er dagegen gelb, indem das freie Quecksilber verdunstet. - Sowohl die Oxydation als die Verdunstung schreitet bei gewöhnlicher Temperatur nur langsam vorwärts. - In einer abgesperrten Luftmenge vermag der feuchte Niederschlag beinahe die ganze Menge des vorhandenen Sauerstoffs zu absorbiren.

3. Bei $100^{\circ}$ schreiten die erwälnnten Aenderungen schneller vorwärts; bei dieser Temperatur und freiem Luftzutritt wird deshalb der Niederschlag bald gelb. Der gelbe Rest ist hier kleiner als unter obigen Bedingungen, da ein Theil des Quecksilberoxyduls zerlegt, ein anderer Theil oxydirt wird.

4. Das in dem Niederschlage enthaltene freie Quecksilber kann quantitativ mittelst Goldchlorid auf die unten unter $\&$ angedeutete Weise bestimmt werden. Die Mengen der beiden anderen Bestandtheile sind dann durch Berechnung leicht $z u$ finden.

5. Flüssiges Quecksilber kann eine so bedeutende Menge Quecksilberoxyd aufnehmen, dass eine salbenähnliche $\mathrm{Mi}$ schung entsteht. Es vermag gleichfalls andere specifisch schwere Metalloxyde aufzunehmen. Dass gewöhnliches Quecksilber an der Luft matt wird, braucht nicht der Einwirkung des Sauerstoffs auf gelöste fremde Metalle zugeschrieben zu werden.

6. In dem fein zertheilten Zustande, worin das Quecksilber in diesen Niederschlägen vorhanden ist, erleidet es bei gewöhnlicher Temperatur keine Oxydation an der Luft.

7. Bei gewöhnlicher Temperatur vermag eine abgesperrte Luftmenge nur einen sehr geringen Theil derjenigen 
472 Curtius u. Koch: Ueber Diazobernsteinsäure etc.

Menge Quecksilberdämpfe aufzunehmen, welche nach anderen Bestimmungen der Sättigungscapacität derselben entsprechen sollte.

8. Quecksilberdämpfe werden leicht von Goldchlorid absorbirt, und reduciren das Gold aus demselben (4). Die Reaction ist so fein, dass die Flüchtigkeit des Quecksilbers bei gewöhnlicher Temperatur auf diese Weise innerhalb weniger Minuten nachgewiesen werden kann. Dadurch ist u. a. auch die Flüchtigkeit des Quecksilbers bei $-8^{0}$ und unter Wasser nachgewiesen worden.

Quecksilberdämpfe reduciren ebenfalls Silbernitrat und Platinchlorid.

\section{Diazo - und Azoverbindungen der Fettreihe.}

II. A bhandlung.

Veber Diazobernsteinsänre, Diazosuccinaminsäure. $\alpha$-1)iazopropionsänre und ihre Derivate; von

Th. Curtius und Franz Koch.

Chlorhydrate der Asparaginsäureäther.

Die salzsauren A ether der leicht zugänglichen $\dot{A}$ sparaginsäure') sind leider nur schwierig in reinem $\mathrm{Zu}$ stande zu gewinnen. Die doppelt alkylirte Säure, welche man durch anhaltendes Kochen mit alkoholischer Salzsäure erhält, giebt allein beständige Diazoverbinclungen. Die Verbindungen sind in Wasser und Alkohol sehr leicht löslich.

Asparaginsäurediäthyläther-Chlorhydrat

$$
\begin{aligned}
& \mathrm{CHNH}_{2} \mathrm{COOC}_{2} \mathrm{H}_{5} \\
& \mathrm{CH}_{2} \mathrm{COOC}_{2} \mathrm{H}_{5}
\end{aligned}
$$

Sternförmig gruppirte Nädelchen aus Alkohol, welche bei $95^{\circ}$ erweichen. Zerfliesst an der Luft.

1) Curtius u. Koch: Ber. 18, 1294; Koch: Inauguraldissertat., Klausenburg 1885. 